\title{
Metallothionein 3 Expression in Normal Skin and Malignant Skin Lesions
}

\author{
Bartosz Pula • Tadeusz Tazbierski • Aleksandra Zamirska • Bozena Werynska • \\ Andrzej Bieniek • Jacek Szepietowski • Janusz Rys • Piotr Dziegiel • \\ Marzena Podhorska-Okolow
}

Received: 2 December 2013 / Accepted: 28 May 2014 / Published online: 13 July 2014

(C) The Author(s) 2014. This article is published with open access at Springerlink.com

\begin{abstract}
Metallothionein-3 (MT-3) has been shown to be expressed in several malignancies and to have an impact on patients' survival in breast and urinary bladder cancer cases. However, its expression has not been determined in normal skin or in its malignant lesions. MT-3 expression was studied using immunohistochemistry in 17 cases of normal skin, 18 of actinic keratosis (AK), 39 of squamous cell carcinoma (SCC), and 23 of basal cell carcinoma (BCC). Low MT-3 expression was observed in normal skin epidermis with faint or no expression in the epidermis basal layer. Significantly higher MT-3 expression was noted in AK $(P=0.007)$ and SCC $(P<0.0001)$, as compared with normal skin epidermis. BCC cases were characterized by the lowest MT-3 expression of all the examined groups, which was significantly lower in comparison to normal skin epidermis, AK, and SCC ( $P=0.009$; $P<0.0001$ and $P<0.0001$, respectively). In conclusion, MT-3 may be involved in the development of SCC.
\end{abstract}

Bartosz Pula and Tadeusz Tazbierski contributed equally

B. Pula · T. Tazbierski $\cdot$ P. Dziegiel $\cdot$ M. Podhorska-Okolow $(\bowtie)$

Department of Histology and Embryology, Medical University of

Wroclaw, Chalubinskiego 6a, 50-368 Wroclaw, Poland

e-mail: marzenna.podhorska-okolow@umed.wroc.pl

A. Zamirska $\cdot$ A. Bieniek $\cdot$ J. Szepietowski

Department and Clinic of Dermatology, Venereology and

Allergology, Medical University of Wroclaw, Wroclaw, Poland

B. Werynska

Department of Pulmonology and Pulmonary Tumors, Medical

University of Wroclaw, Wroclaw, Poland

J. Rys

Department of Tumor Pathology, Maria Sklodowska-Curie

Memorial Institute Oncology Center, Krakow, Poland

P. Dziegiel

Department of Physiotherapy, University School of Physical

Education, Wroclaw, Poland
Keywords Metallothionein-3 · Skin cancer · Squamous cell carcinoma $\cdot$ Basal cell carcinoma

\section{Introduction}

Nonmelanoma skin cancer (NMSC) is the most frequent form of neoplastic disease in Caucasian populations [1]. Since the 1960 s, its overall incidence has increased by approximately $3-$ $8 \%$ per year $[1,2]$. NMSCs are mainly represented by two histological tumor types: basal cell carcinoma (BCC) and squamous cell carcinoma (SCC) [1,3]. Although BCC is seen up to five times more frequently in patients, it is considered to be an exclusively local malignant tumor due to the fact that metastases (to lymph nodes and other organs) are rarely observed $[1,4,5]$. However, SCC is considered a malignant skin tumor and is responsible for the majority of NMSC associated deaths [3]. Almost $80 \%$ of all BCCs arise on sun-exposed skin, developing mainly on the head and neck regions $[4,5]$. It has been shown that SCC may develop either from a precursor lesion, such as actinic keratosis (AK), or de novo. Although it is thought that a significant fraction of SCCs evolve from AK, the potential of malignant transformation cannot be predicted from clinical characteristics and is difficult to assess [3]. Unlike SCCs, BCCs do not have precursor lesions and instead appear de novo as a tumor which can usually be classified into one of two main groups: nodular BCCs are the most common, presenting as a small pearly papule with well-developed peripheral cells palisading. Superficial BCCs macroscopically manifest as scaly erythematous plaques and buds of atypical basal cells arising from the basal layer of epidermis $[5,6]$. The abovementioned forms manifest low aggressiveness and may often be cured through local excision, however also histopathological BCC types of higher aggressiveness and frequent local recurrences are distinguished e.g. micronodular, morpheaform, infiltrative and metatypic types $[5,6]$. 
Metallothioneins (MTs) are a family of small $(6-7 \mathrm{kDa})$, intracellular, nonenzymatic family of proteins that are highly conserved among species [7]. MTs are characterized by high cysteine content in their polypeptide chain [8]. The high number of thiol $(-\mathrm{SH})$ groups enables them to bind metals, such as $\mathrm{Zn}, \mathrm{Cd}, \mathrm{Cu}$, and $\mathrm{Hg}$, and to transfer $\mathrm{Cu}$ and $\mathrm{Zn}$ to the catalytic sites of various enzymes [9, 10]. MTs are encoded by a family of genes located on human chromosome 16q13, and four main groups of these proteins can be distinguished (MT1, MT-2, MT-3, MT-4) [11]. Lines of evidence suggest that MT-1 and MT-2 play important roles in various cellular processes - in both normal and cancer cells - such as detoxification of heavy metals, homeostasis of zinc and copper ions, and protection of cell DNA against oxidative stress damage, proliferation, and apoptosis [7, 8, 10, 12-14]. Elevated MT-1/2 expression has been associated with poor patient prognosis in ovarian, renal, lung, and colorectal cancer, as well in soft tissue sarcomas [12, 15-20]. Although numerous studies have been performed on the role of MT-1/2 isoforms in various normal and pathological processes, little is known yet regarding the role of metallothionein-3 (MT-3) in cancer cells.

MT-3 was first identified in rat brain extracts in the course of Alzheimer's disease and possesses an unique neuronal cell growth inhibitory property, not exerted by other members of the family, (such as MT-1/2) [21]. On account of this property, MT-3 was first described as a growth-inhibitory factor (GIF) [21, 22]. Its expression was initially reported to be very restricted to the nervous tissues, but further studies proved its wider distribution in the human body [22-28]. The results of recent research concerning the role of MT3 in neoplastic diseases remain ambiguous and are frequently inconsistent. It has been shown that, in human bladder, breast, and prostate cancer, the expression of MT-3 increases [22, $24,27]$. On the contrary, in esophageal squamous cell cancer and adenocarcinoma of the esophagus - as well as in gastric cancer-MT-3 expression decreases, as compared with normal tissue [23, 29, 30]. Although the expression of MT-1/2 has been intensively studied in normal and malignant skin lesions, no information concerning MT-3 expression is currently available [31, 32]. It has been shown that MT- $1 / 2$ expression increases significantly with the progression from normal skin to AK, with the highest expression noted for SCC [32]. Moreover, MT-1/2 has been shown to be positively correlated with Ki-67 antigen expression in AK, SCC, and $\mathrm{BCC}$-confirming its role in regulation of cell proliferation $[31,32]$.

Taking into account that MT-1/2 may have an impact on carcinogenic processes in the skin, we analyzed the expression of MT-3 using immunohistochemical methods in cases of normal skin, $\mathrm{AK}, \mathrm{SCC}$, and $\mathrm{BCC}$, with regard to the clinical and pathological characteristics of patients.

\section{Material and Methods}

\section{Patients and Tissue Samples}

The study was performed on tissue samples obtained from patients during the resection of skin lesions due to suspicion of clinical cancer in the Department and Clinic of Dermatology, Venereology, and Allergology, Medical University of Wroclaw. The study group consisted of 97 skin samples, of which 17 were diagnosed as normal skin, 18 as AK, 39 as SCC and, 23 as BCC (12 of the nodular type and 11 of the superficial type).

Resected tissue samples were fixed in $10 \%$ buffered formalin and embedded in paraffin following prior dehydration. Six micrometer-thick sections were evaluated independently by two pathologists to verify the diagnosis and to assess the clinical and pathological characteristics of the analyzed SCC cases. The four-grade Broders scale classifies the differentiation and keratinization of tumor cells, and was employed here to determine the malignancy grade of the studied SCC tumors [33]. It is encoded as follows: G1 (>75\% keratinized cells), G2 (50-75\% keratinized cells), G3 (25-50\% keratinized cells), and G4 ( $<25 \%$ keratinized cells). In addition, the degree of keratinization and the depth of inflammatory infiltrate were assessed. The mean patient age was $72.5 \pm 13.2$ (range 37 to 97) years. The clinical and pathological data of the SCC patients are summarized in Table 1.

\section{Immunohistochemistry (IHC)}

For IHC reactions, four micrometer-thick sections were freshly cut and deparaffinized in xylene with subsequent rehydration in alcohol (absolute, $96 \%, 70 \%$ ), with 5 min' incubation each. Sections were boiled for $20 \mathrm{~min}$ in Target Retrieval Buffer (high $\mathrm{pH}$ for MT-3 and low $\mathrm{pH}$ for Ki-67 antigen) using a PT Link (Pre-Treatment Module for Tissue Specimens), in order to retrieve the studied antigens. Sections were then rinsed in TBS buffer with $0.05 \%$ Tween. Then the EnVision $^{\mathrm{TM}}$ FLEX Detection System was employed. EnVision $^{\mathrm{TM}}$ FLEX Peroxidase-Blocking Reagent was used to block endogenous peroxidase, with 5 min' incubation. Following rinsing in TBS with $0.05 \%$ Tween, the primary antibodies were applied: anti-MT-3, a rabbit polyclonal antibody raised against GGEAAEAEAEKC peptide (1:200, Invitrogen, Carlsbad, California, USA) and anti-Ki-67 (ready to use, Dako Cytomation, Glostrup, Denmark). Following $20 \mathrm{~min}$ of incubation, the slides were rinsed in TBS with $0.05 \%$ Tween, and the secondary antibody conjugated with horseradish peroxidase was used (EnVision ${ }^{\mathrm{TM}}$ FLEX/HRP), with incubation for $20 \mathrm{~min}$. The MT-3 and Ki-67 reaction was visualized using freshly prepared substrate for horseradish peroxidase (diaminobenzidine, EnVision ${ }^{\mathrm{TM}}$ Working Solution), with incubation for $10 \mathrm{~min}$. Additionally, all slides were 
Table. 1 Patient and tumor characteristics of the squamous cell carcinoma cases analyzed

\begin{tabular}{ll}
\hline Parameter & No. of cases $(\%)$ \\
\hline Sex & \\
Male & $22(56.4 \%)$ \\
Female & $17(44.6 \%)$ \\
Differentiation & \\
Keratotic & $31(79.5 \%)$ \\
Akeratotic & $8(20.5 \%)$ \\
Broders scale & \\
G1 & $7(17.9 \%)$ \\
G2 & $10(25.7 \%)$ \\
G3 & $14(35.9 \%)$ \\
G4 & $8(20.5 \%)$ \\
Depth of inflammatory infiltration & \\
Epidermis & $9(23.1 \%)$ \\
Subcutaneous tissue & $30(76.9 \%)$ \\
Sun exposure & $36(92.3 \%)$ \\
Exposed & \\
Occulted & \\
\hline
\end{tabular}

counterstained using EnVision ${ }^{\mathrm{TM}}$ FLEX Hematoxylin and 5 min' incubation. Eventually, after dehydration in graded ethanol concentrations ( $70 \%, 96 \%$, absolute) and in xylene, all slides were closed with coverslips in SUB-X Mounting Medium in Coverslipper. All reagents and equipment, except for the MT-3 antibody, were purchased from Dako Cytomation.

\section{Evaluation of IHC Reactions}

All IHC reactions were assessed using a BX41 light microscope (Olympus, Tokyo, Japan) independently by two pathologists, who were blinded to patient clinico-pathological data. In case of discrepancy between the pathologist, the staining was discussed until a consensus has been achieved. The expression intensity of MT-3 in the tumor cells was evaluated using the semi-quantitative 12-point immunoreactive score (IRS) of Remmele and Stegner, utilized previously in our studies concerning MT1/2 expression [31, 34]. The cytoplasmic MT3 IRS reaction score was calculated in each case, taking into account both the percentage of positive cells $(0$ points: no cells with positive reaction; 1 point: $1-10 \%$ cells; 2 points: $11-50 \%$; 3 points: $51-80 \%$; 4 points: over $80 \%$ cells with positive reaction) and the intensity of the reaction $(0$ : no reaction; 1: low intensity of the reaction color; 2 : moderate intensity of the reaction color; 3 : intense color of the reaction). The final score represents the product of these two parameters and ranges from 0 to 12 points.

The expression of Ki-67 antigen in healthy skin and its lesions was assessed by the proportion of positive cells from all epidermal (normal skin and $\mathrm{AK}$ ) or tumor cells (BCC and SCC) in whole tissue sections, and was coded as follows: 0 points for no reaction, 1 point for $1-10 \%, 2$ points for $11-$ $25 \%, 3$ points for $26-50 \%$, and 4 points for $>50 \%$ positive cells.

\section{Statistical Analysis}

The results were subjected to statistical analysis using Prism 5.0 (GraphPad Software, La Jolla, CA, USA). The ShapiroWilk test was employed to test the distribution. MannWhitney's $U$-test was used to assess the differences in MT-3 expression between the two groups. The correlation between the expression intensity of the selected markers was evaluated using the Spearman correlation test, or the Pearson test in the case of patient age analyses. The results were regarded as statistically significant for $P<0.05$.

\section{Results}

A cytoplasmic reaction in MT-3 immunostained slides was observed in $89(91.8 \%)$ of all analyzed cases. No staining was noted in the remaining 8 (8.2\%) cases (Fig. 1), one of which involved normal healthy skin and seven of which involved BCC. No nuclear MT-3 expression pattern could be seen in the keratinocytes of normal skin epidermis, $\mathrm{AK}$, or in the tumor cells of BCC and SCC. MT-3 expression was mostly noted in the suprabasal layer of the epidermis in normal skin and $\mathrm{AK}$ lesions, with only scant faint expression noted in the basal layer (Fig. 1).

Low MT-3 expression level was observed in normal skin epidermis, scoring at the average of $2.65(\mathrm{SD} \pm 1.69)$ on the IRS scale. A significantly higher MT-3 expression was noted in AK (IRS 4.61 $\pm 2.36 ; P=0.007$ ) and SCC (IRS 6.15 \pm 2.35 ; $P<0.0001)$, as compared with normal skin epidermis. The BCC cases were characterized by the lowest intensity of MT-3 expression of all the examined groups (IRS 1.30土 1.11), being significantly lower in comparison to normal skin epidermis, AK, and SCC $(P=0.009 ; P<0.0001$ and $P<0.0001$, respectively) (Fig. 2).

Nuclear expression of Ki-67 antigen was observed in all of the analyzed cases. Its expression was lowest in healthy skin epidermis (1.18 \pm 0.64$)$, and was significantly lower than in the cases of BCC (2.16 $\pm 0.92 ; P=0.006)$, AK $(2.17 \pm 0.92 ; P=$ $0.002)$, and SCC (2.02 $\pm 1.06 ; P=0.0062)$ (Fig. 3).

The statistical analysis of MT-3 expression in SCC cases did not reveal any significant differences in SCC as regarding patient age (Pearson correlation test), sex, depth of inflammatory infiltration, malignancy grade, differentiation (keratotic vs. akeratotic), or sun exposure (Mann-Whitney test, respectively). Similar results were observed for Ki-67 antigen expression. Moreover, no significant correlation was noted 
Fig. 1 Cytoplasmic

metallothionein-3 expression (a) in healthy skin epidermis, (b) in actinic keratosis, (c) in squamous cell carcinoma, and (d) in basal cell carcinoma. Magnification $\times$ 200

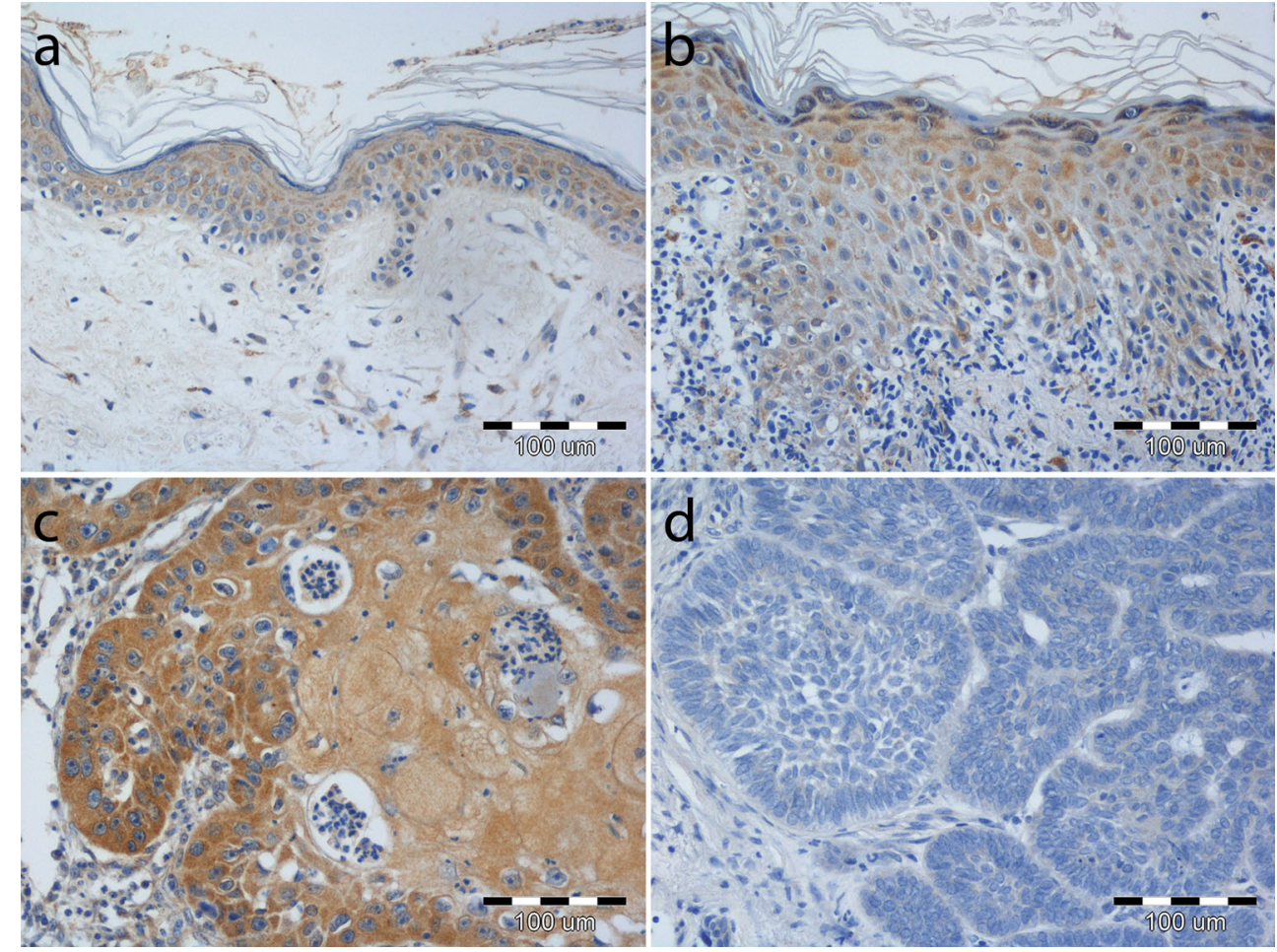

between MT-3 and Ki-67 antigen expression in normal skin and its lesions (BCC, AK, SCC; Spearman correlation test).

\section{Discussion}

The MT-3 gene was first identified by Palmiter et al., and initial studies demonstrated that MT-3 expression was limited mainly to neuronal tissue $[35,36]$. Nevertheless, recent research has revealed a broader physiological distribution of the molecule not only in normal tissue, but also in human prostate,

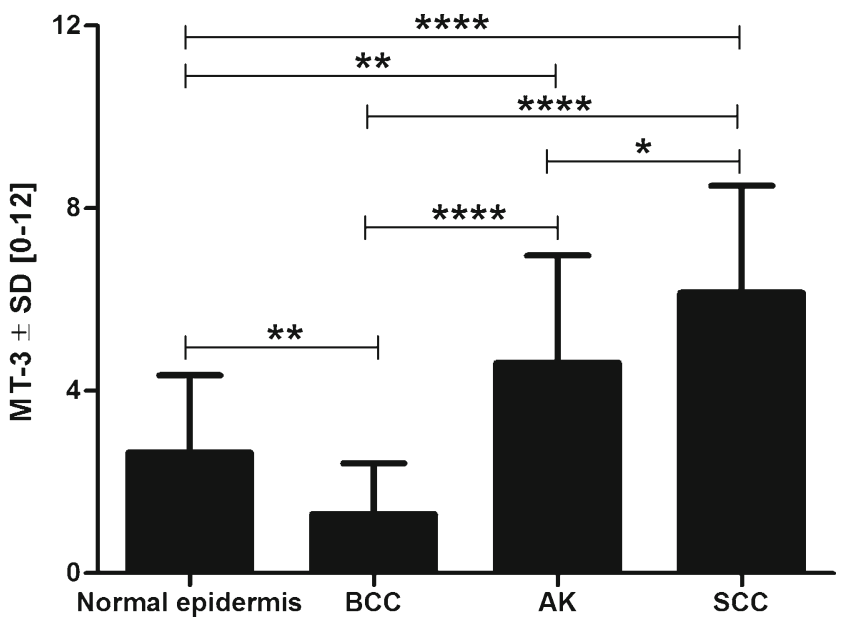

Fig. 2 Differentiated cytoplasmic metallothionein-3 (MT-3) expression with regard to the type of analyzed sample. * $P<0.05$; ** $P<0.005$; *** $P<0.0005$; **** $P<0.0001$ (Mann-Whitney test); AK: actinic keratosis; BCC: basal cell carcinoma; SCC: squamous cell carcinoma esophagus, breast, and non-small-cell lung cancers [24, 25, $28,37,38]$. Although MT-3 expression has been identified in cancer cells, its exact role in oncological diseases requires further clarification. Augmented MT-3 expression was observed in neoplastic cells of breast, prostate, bladder, and non-small-cell lung cancer [22, 24, 27, 38]. In contrast, in human esophageal cancers and gastric cancer, MT-3 expression has been seen to be frequently downregulated due to the increased DNA methylation in comparison with nonmalignant tissues of these organs [23, 29, 30].

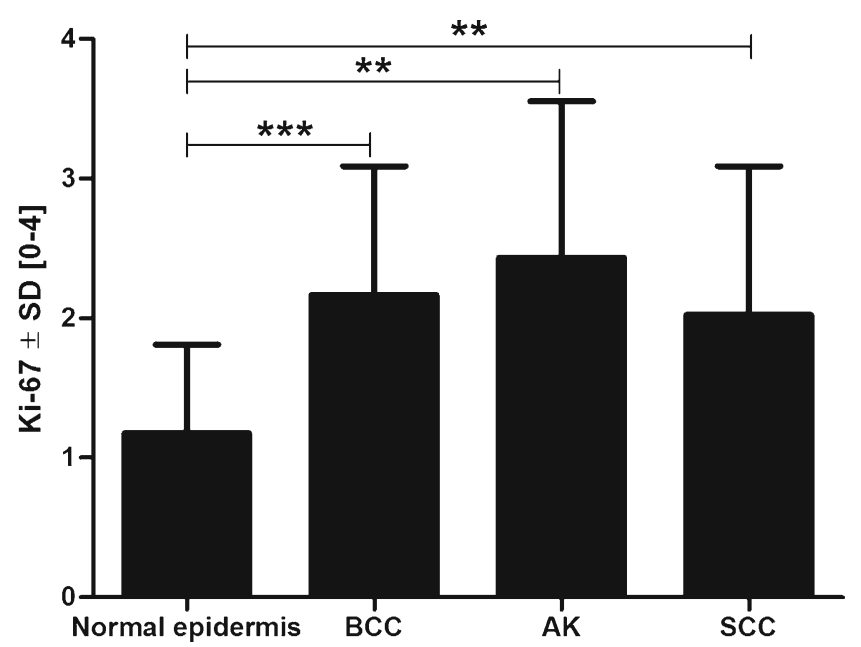

Fig. 3 Nuclear Ki-67 antigen expression in regard to the type of analyzed sample. ** $P<0.005$; *** $P<0.0005$ (Mann-Whitney test); AK: actinic keratosis; BCC: basal cell carcinoma; SCC: squamous cell carcinoma 
In this study, we demonstrated for the first time MT-3 expression in normal skin keratinocytes. Additionally, its expression seems to be associated with the stratification of the epithelium, as cells in the basal layer are characterized by lower MT-3 expression levels (including zero expression) than in the case of the more differentiated cells of the suprabasal layers. Similar results have been obtained in regard to MT-4 [39]. In contrast, MT-1 and MT-2 probably exhibit different paths of expression and regulation, as less differentiated and undifferentiated cells from the basal layer demonstrate higher expression, as compared to suprabasal layers of keratinocytes [32].

Actinic keratosis is considered a premalignant skin lesion that can evolve to SCC $[3,32]$. The observation of changes in the MT-3 expression intensity in normal skin epidermis, AK, and SCC point to the potential role of this protein in skin carcinogenesis. AK cases exhibit an intermediate MT-3 expression, which is higher in comparison to that noted in normal skin epidermis, but lower when compared to that of SCC cancer cells. Similar results regarding MT-1/2 were obtained by Zamirska et al., in whose work SCC cases were characterized by higher expression in AK, with the lowest expression in normal skin epidermis [32]. This observation may indicate the role of MT-3 in the development of SCC. Interestingly, we have also observed different intensities of its expression in cases of BCC and SCC, as significantly higher MT-3 expression was observed in the latter NMSC type. This observation is also consistent with the MT-3 expression pattern noted in healthy skin and AK lesions, in which only a scant, faint expression was visible in the basal cells. It is possible that MT- 3 expression in BCC and basal cells may be the result of similar regulation processes based on DNA methylation, as has been observed in gastric and esophageal cancers $[23,30]$. On the other hand, keratinocytes of the suprabasal layers are characterized by higher levels of MT-3 expression, which increases with the malignant potential of the lesion, the peak being achieved in SCC. These observations may be partially clarified by the regulation of zinc ion homeostasis in healthy and malignant skin lesions. Zinc ions have been shown to mediate numerous processes in skin biology, ranging from keratinocyte differentiation, through wound healing, to cancer development [40, 41]. Moreover, zinc deficiency was frequently present in patients with squamous cell carcinomas diagnosed in oral cavity, oropharynx and larynx [42]. MTs have been shown to regulate zinc ion homeostasis in response to stress, and therefore might serve as a key source of the exchangeable zinc ions needed for regulating transcription factor activity, and ultimately, diverse cellular response signals in SCC cancer cells $[8,43]$. Although no studies have focused on revealing the relationship of MT-3 with metal ion homeostasis, this path in the carcinogenesis of the skin remains to be clarified. In this study we aimed at defining the role of MT-3 in the regulation of cellular proliferation, which was assessed in this study by examining the expression intensity of the Ki-67 antigen. However, no correlation between those two markers could be disclosed, indicating that MT-3 may probably impact other cellular process than proliferation in skin lesions. Recently, MT-3 was shown to be involved in the regulation of lysosomal function and autophagy in neurons and astrocytes, and may also potentially influence this processes during skin carcinogenesis [44, 45]. To our knowledge, the exact role of MT-3 expression in regard to autophagic processes in cancer cells has not yet been investigated. MT3 was also shown to protect neurons from hypoxia or DNA-induced damage via increased activity of NF- $\mathrm{KB}$ and protein kinase B (Akt) signaling pathway [46]. This may also be one of potential mechanism of actions of MT-3, as it was shown that Akt is overexpressed in SCC [47].

In our study, we did not observe any significant relationship between MT-3 expression in SCC cancer cells and any clinical and pathological parameters that might point to the role of MT-3 in SCC progression and prognosis. Our results are comparable to those obtained during the examination of esophageal and gastric cancers, where MT-3 expression had no impact on patients' clinical or pathological data or on patient survival $[23,29,30]$. However, in the study of Sens et al., MT-3 expression was up-regulated in human bladder cancer tumor cells, and was positively correlated with the tumor malignancy grade [27]. In addition, in breast cancer, MT-3 expression is considered to be a marker of poor prognosis $[22,37]$. Although, we did not notice any correlations between MT-3 expression intensity in cancer cells and SCC patients clinico-pathological data, the prognostic impact of MT-3 expression remains to be yet determined. In the current study we had no information concerning the survival time of SCC patients, therefore we could not definitely define the potential utility of MT-3 as a new prognostic marker of this malignancy.

In summary, we have shown for the first time that MT-3 may be potentially involved in the development of SCC. Moreover, the varying expression levels of MT-3 observed by us in SCC and BCC confirm the differing biology of both these malignant skin lesions.

Acknowledgments The authors thank Bozena Przygodzka, Agnieszka Baranska, Elzbieta Polejko, and Aleksandra Jethon for their technical assistance. The research was supported by Wroclaw EIT+Research Center under the project entitled "Biotechnologies and advanced medical technologies", BioMed (POIG.01.01.02-02-003/08) financed by the European Regional Development Fund (Operational Programme Innovative Economy, 1.1.2).

Open Access This article is distributed under the terms of the Creative Commons Attribution License which permits any use, distribution, and reproduction in any medium, provided the original author(s) and the source are credited. 


\section{References}

1. Marks R (1995) The epidemiology of non-melanoma skin cancer: who, why and what can we do about it. J Dermatol 22(11):853-857

2. Tufaro AP, Chuang JC, Prasad N, Chuang A, Chuang TC, Fischer AC (2011) Molecular markers in cutaneous squamous cell carcinoma. Int J Surg Oncol 2011:231475. doi:10.1155/2011/231475

3. Zalaudek I, Whiteman D, Rosendahl C, Menzies SW, Green AC, Hersey P, Argenziano G (2011) Update on melanoma and nonmelanoma skin cancer. Annual Skin Cancer Conference 2011, Hamilton Island, Australia, 5-6 August 2011. Expert Rev Anticancer Ther 11(12):1829-1832. doi:10.1586/era.11.180

4. Rubin AI, Chen EH, Ratner D (2005) Basal-cell carcinoma. N Engl J Med 353(21):2262-2269. doi:10.1056/NEJMra044151

5. Crowson AN (2006) Basal cell carcinoma: biology, morphology and clinical implications. Mod Pathol 19(Suppl 2):S127-147. doi:10. 1038/modpathol.3800512

6. Goppner D, Leverkus M (2011) Basal cell carcinoma: from the molecular understanding of the pathogenesis to targeted therapy of progressive disease. J Skin Cancer 2011:650258. doi:10.1155/2011/650258

7. Coyle P, Philcox JC, Carey LC, Rofe AM (2002) Metallothionein: the multipurpose protein. Cell Mol Life Sci 59(4):627-647

8. Dziegiel P (2004) Expression of metallothioneins in tumor cells. Pol J Pathol 55(1):3-12

9. Nielsen AE, Bohr A, Penkowa M (2007) The Balance between Life and Death of Cells: Roles of Metallothioneins. Biomark Insights 1:99-111

10. Pula B, Domoslawski P, Podhorska-Okolow M, Dziegiel P (2012) Role of metallothioneins in benign and malignant thyroid lesions. Thyroid Res 5(1):26. doi:10.1186/1756-6614-5-26

11. Thirumoorthy N, Shyam Sunder A, Manisenthil Kumar K, Senthil Kumar M, Ganesh G, Chatterjee M (2011) A review of metallothionein isoforms and their role in pathophysiology. World J Surg Oncol 9:54. doi:10.1186/1477-7819-9-54

12. Dziegiel P, Salwa-Zurawska W, Zurawski J, Wojnar A, Zabel M (2005) Prognostic significance of augmented metallothionein (MT) expression correlated with $\mathrm{Ki}-67$ antigen expression in selected soft tissue sarcomas. Histol Histopathol 20(1):83-89

13. Surowiak P, Matkowski R, Materna V, Gyorffy B, Wojnar A, Pudelko M, Dziegiel P, Kornafel J, Zabel M (2005) Elevated metallothionein (MT) expression in invasive ductal breast cancers predicts tamoxifen resistance. Histol Histopathol 20(4):1037-1044

14. Wojnar A, Pula B, Piotrowska A, Jethon A, Kujawa K, Kobierzycki C, Rys J, Podhorska-Okolow M, Dziegiel P (2011) Correlation of intensity of MT-I/II expression with Ki-67 and MCM-2 proteins in invasive ductal breast carcinoma. Anticancer Res 31(9):3027-3033

15. Surowiak P, Materna V, Kaplenko I, Spaczynski M, Dietel M, Lage H, Zabel M (2005) Augmented expression of metallothionein and glutathione S-transferase pi as unfavourable prognostic factors in cisplatin-treated ovarian cancer patients. Virchows Arch 447(3): 626-633. doi:10.1007/s00428-005-1228-0

16. Surowiak P, Materna V, Maciejczyk A, Pudelko M, Markwitz E, Spaczynski M, Dietel M, Zabel M, Lage H (2007) Nuclear metallothionein expression correlates with cisplatin resistance of ovarian cancer cells and poor clinical outcome. Virchows Arch 450(3):279285. doi:10.1007/s00428-006-0362-7

17. Tuzel E, Kirkali Z, Yorukoglu K, Mungan MU, Sade M (2001) Metallothionein expression in renal cell carcinoma: subcellular localization and prognostic significance. J Urol 165(5):1710-1713

18. Dziegiel P, Jelen M, Muszczynska B, Maciejczyk A, Szulc A, Podhorska-Okolow M, Cegielski M, Zabel M (2004) Role of metallothionein expression in non-small cell lung carcinomas. Rocz Akad Med Bialymst 49(Suppl 1):43-45
19. Werynska B, Pula B, Muszczynska-Bernhard B, Gomulkiewicz A, Piotrowska A, Prus R, Podhorska-Okolow M, Jankowska R, Dziegiel $\mathrm{P}$ (2013) Metallothionein $1 \mathrm{~F}$ and 2A overexpression predicts poor outcome of non-small cell lung cancer patients. Exp Mol Pathol 94(1):301-308. doi:10.1016/j.yexmp.2012.10.006

20. Dziegiel P, Forgacz J, Suder E, Surowiak P, Kornafel J, Zabel M (2003) Prognostic significance of metallothionein expression in correlation with Ki-67 expression in adenocarcinomas of large intestine. Histol Histopathol 18(2):401-407

21. Uchida Y, Tomonaga M (1989) Neurotrophic action of Alzheimer's disease brain extract is due to the loss of inhibitory factors for survival and neurite formation of cerebral cortical neurons. Brain Res 481(1): 190-193

22. Somji S, Garrett SH, Zhou XD, Zheng Y, Sens DA, Sens MA (2010) Absence of Metallothionein 3 Expression in Breast Cancer is a Rare, But Favorable Marker of Outcome that is Under Epigenetic Control. Toxicol Environ Chem 92(9):1673-1695. doi:10.1080/ 02772241003711274

23. Deng D, El-Rifai W, Ji J, Zhu B, Trampont P, Li J, Smith MF, Powel SM (2003) Hypermethylation of metallothionein-3 CpG island in gastric carcinoma. Carcinogenesis 24(1):25-29

24. Garrett SH, Sens MA, Shukla D, Nestor S, Somji S, Todd JH, Sens DA (1999) Metallothionein isoform 3 expression in the human prostate and cancer-derived cell lines. Prostate 41(3):196-202

25. Garrett SH, Sens MA, Todd JH, Somji S, Sens DA (1999) Expression of MT-3 protein in the human kidney. Toxicol Lett 105(3):207-214

26. Kim D, Garrett SH, Sens MA, Somji S, Sens DA (2002) Metallothionein isoform 3 and proximal tubule vectorial active transport. Kidney Int 61(2):464-472. doi:10.1046/j.1523-1755. 2002.00153.x

27. Sens MA, Somji S, Lamm DL, Garrett SH, Slovinsky F, Todd JH, Sens DA (2000) Metallothionein isoform 3 as a potential biomarker for human bladder cancer. Environ Health Perspect 108(5):413418

28. Somji S, Garrett SH, Sens MA, Gurel V, Sens DA (2004) Expression of metallothionein isoform 3 (MT-3) determines the choice between apoptotic or necrotic cell death in $\mathrm{Cd}+2$-exposed human proximal tubule cells. Toxicol Sci 80(2):358-366. doi:10.1093/toxsci/kfh158

29. Smith E, Drew PA, Tian ZQ, De Young NJ, Liu JF, Mayne GC, Ruszkiewicz AR, Watson DI, Jamieson GG (2005) Metallothionien 3 expression is frequently down-regulated in oesophageal squamous cell carcinoma by DNA methylation. Mol Cancer 4:42. doi:10.1186/ 1476-4598-4-42

30. Peng D, Hu TL, Jiang A, Washington MK, Moskaluk CA, SchneiderStock R, El-Rifai W (2011) Location-specific epigenetic regulation of the metallothionein 3 gene in esophageal adenocarcinomas. PLoS One 6(7):e22009. doi:10.1371/journal.pone.0022009

31. Bieniek A, Pula B, Piotrowska A, Podhorska-Okolow M, Salwa A, Koziol M, Dziegiel P (2012) Expression of metallothionein I/II and Ki-67 antigen in various histological types of basal cell carcinoma. Folia Histochem Cytobiol 50(3):352357. doi:10.5603/19744

32. Zamirska A, Matusiak L, Dziegiel P, Szybejko-Machaj G, Szepietowski JC (2012) Expression of metallothioneins in cutaneous squamous cell carcinoma and actinic keratosis. Pathol Oncol Res 18(4):849-855. doi:10.1007/s12253-012-9513-0

33. Anneroth G, Batsakis J, Luna M (1987) Review of the literature and a recommended system of malignancy grading in oral squamous cell carcinomas. Scand J Dent Res 95(3):229-249

34. Remmele W, Stegner HE (1987) Recommendation for uniform definition of an immunoreactive score (IRS) for immunohistochemical estrogen receptor detection (ER-ICA) in breast cancer tissue. Pathologe 8(3):138-140

35. Palmiter RD, Findley SD, Whitmore TE, Durnam DM (1992) MTIII, a brain-specific member of the metallothionein gene family. Proc Natl Acad Sci U S A 89(14):6333-6337 
36. Uchida Y, Takio K, Titani K, Ihara Y, Tomonaga M (1991) The growth inhibitory factor that is deficient in the Alzheimer's disease brain is a 68 amino acid metallothionein-like protein. Neuron 7(2):337-347

37. Sens MA, Somji S, Garrett SH, Beall CL, Sens DA (2001) Metallothionein isoform 3 overexpression is associated with breast cancers having a poor prognosis. Am J Pathol 159(1):21-26. doi:10. 1016/S0002-9440(10)61668-9

38. Werynska B, Pula B, Muszczynska-Bernhard B, Gomulkiewicz A, Jethon A, Podhorska-Okolow M, Jankowska R, Dziegiel P (2013) Expression of metallothionein-III in patients with non-small cell lung cancer. Anticancer Res 33(3):965-974

39. Quaife CJ, Findley SD, Erickson JC, Froelick GJ, Kelly EJ, Zambrowicz BP, Palmiter RD (1994) Induction of a new metallothionein isoform (MT-IV) occurs during differentiation of stratified squamous epithelia. Biochemistry 33(23):7250-7259

40. Lamore SD, Wondrak GT (2011) Zinc pyrithione impairs zinc homeostasis and upregulates stress response gene expression in reconstructed human epidermis. Biometals 24(5):875-890. doi:10.1007/ s10534-011-9441-6

41. Kumar P, Lal NR, Mondal AK, Mondal A, Gharami RC, Maiti A (2012) Zinc and skin: a brief summary. Dermatol Online J 18(3):1

42. Prasad AS (1998) Zinc deficiency in humans: a neglected problem. J Am Coll Nutr 17(6):542-543
43. Pedersen MO, Larsen A, Stoltenberg M, Penkowa M (2009) The role of metallothionein in oncogenesis and cancer prognosis. Prog Histochem Cytochem 44(1):29-64. doi:10.1016/j.proghi.2008.10. 001

44. Lee SJ, Koh JY (2010) Roles of zinc and metallothionein-3 in oxidative stress-induced lysosomal dysfunction, cell death, and autophagy in neurons and astrocytes. Mol Brain 3(1):30. doi: 10.1186/1756-6606-3-30

45. Lee SJ, Park MH, Kim HJ, Koh JY (2010) Metallothionein-3 regulates lysosomal function in cultured astrocytes under both normal and oxidative conditions. Glia 58(10):1186-1196. doi: 10.1002/glia.20998

46. Kim HG, Hwang YP, Han EH, Choi CY, Yeo CY, Kim JY, Lee KY, Jeong HG (2009) Metallothionein-III provides neuronal protection through activation of nuclear factor-kappaB via the TrkA/phosphatidylinositol-3 kinase/Akt signaling pathway. Toxicol Sci 112(2):435-449. doi:10.1093/toxsci/kfp230

47. Bito T, Sumita N, Ashida M, Budiyanto A, Ueda M, Ichihashi M, Tokura Y, Nishigori C (2011) Inhibition of Epidermal Growth Factor Receptor and PI3K/Akt Signaling Suppresses Cell Proliferation and Survival through Regulation of Stat3 Activation in Human Cutaneous Squamous Cell Carcinoma. J Skin Cancer 2011:874571. doi:10.1155/2011/874571 